\title{
Sense of coherence is associated with reduced psychological responses to job stressors among Japanese factory workers
}

\author{
Kayoko Urakawa ${ }^{1,2^{*} \dagger}$, Kazuhito Yokoyama ${ }^{2 \dagger}$ and Hiroaki Itoh ${ }^{2}$
}

\begin{abstract}
Background: Job stress is associated with adverse health effects. The present study was conducted to examine the association between sense of coherence (SOC), as advocated by Antonovsky, and psychological responses to job stressors among Japanese workers.

Methods: A self-administered questionnaire containing a Japanese version of the 13-item SOC scale, the Brief Job Stress Questionnaire, and a self-rated health item were distributed to 1968 workers in X Prefecture. Anonymous responses were recovered by postal mail.

Results: Complete responses were received from 299 workers (response rate 15.2\%, 191 males and 108 females) who consented to participate in the study. Participants were 186 office clerks, 38 sales representatives, 22 technical engineers, 16 service trade workers, eight information processing workers, eight technical experts, and 21 other workers of various types. SOC scores were associated with age, self-rated health, job title, and marriage status. According to regression analyses stratified by gender, SOC was inversely associated with tension, fatigue, anxiety, depression and subjective symptoms in males, and tension, depression and subjective symptoms in females. SOC was positively associated with vigor in both males and females.
\end{abstract}

Conclusions: Having a strong SOC may reduce worker's negative job stress responses and increase their vigor. Longitudinal studies are required to confirm this finding.

Keywords: Sense of coherence, Job stress, Brief Job Stress Questionnaire, Stress reduction

\section{Background}

Approximately 30 years have passed since Aaron Antonovsky [1] proposed the salutogenic model of health. The sense of coherence (SOC) concept, which is based on the salutogenic model, has attracted research attention in the population health field. One's SOC is believed to express the extent to which they have a persistent, enduring but dynamic feeling of confidence that: (1) the stimuli deriving from their internal and external environments in the

\footnotetext{
* Correspondence: adiemus@nurse.medic.mie-u.ac.jp

${ }^{\dagger}$ Equal contributors

'Department of Stress Science, Mie University Graduate School of Medicine, 2-174 Edobashi, Tsu, Mie 514-8507, Japan

${ }^{2}$ Department of Epidemiology and Environmental Health, Juntendo University Faculty of Medicine, 2-1-1 Hongo, Bunkyo-ku, Tokyo 113-8421, Japan
}

\section{Biomed Central

(c) 2012 Urakawa et al.; licensee BioMed Central Ltd. This is an Open Access article distributed under the terms of the Creative Commons Attribution License (http://creativecommons.org/licenses/by/2.0), which permits unrestricted use, distribution, and reproduction in any medium, provided the original work is properly cited. course of living are structured, predictable, and explicable (comprehensibility); (2) resources are available to them to meet the demands posed by these stimuli (manageability); and (3) such demands are challenges, worthy of investment and engagement (meaningfulness) [1-3]. SOC in individuals is assessed by a 13-item scale [4].

Several studies have indicated that SOC modifies of job stress responses. For example, having a strong SOC protects individuals from the effects of stressors at work [5]. Health social workers with a strong SOC experience less burnout than those with a weak SOC [6]. SOC buffers the effects of stressful life events on individuals' mental health status [7]. A study of Japanese civil servants indicated that having a stronger SOC was associated with fewer days of absence from work and fewer adverse physical health symptoms [8]. Among resident physicians, an increase in psychiatric complaints as 
measured by General Health Questionnaire (GHQ) scores was associated with a weak SOC and adverse work conditions as assessed by the Brief Job Stress Questionnaire (BJSQ) [9].

Developed in Japan for use in occupational health check-ups, the BJSQ assesses job stressors and stress responses [10]. The BJSQ is a multi-dimensional questionnaire using four-point Likert scale response options (1 "strongly disagree" to 4 "strongly agree") to measure job stressors and psychological distress such as tension, fatigue, anxiety, depression, and vigor (three items for each) and subjective symptoms (10 items). Quantitative job demand, qualitative job demand, job decision latitude (three items for each) and social support (nine items) are the job stressors measured by the BJSQ, which is essentially based on the demand-controlsupport model [11,12] (in addition, physical job load is measured by one item). All of the BJSQ scales have acceptable levels of internal consistency, reliability and factor-based validity $[13,14]$.

Our previous study [15] demonstrated that GHQ scores were positively associated with job demands as measured by the BJSQ, whereas the scores were inversely associated with SOC scores among Japanese workers in the manufacturing industry, suggesting that having a stronger SOC can reduce the adverse effects of job stress such as psychiatric complaints. The purpose of the present study was to test this hypothesis by examining the association between SOC and the stress responses assessed by the BJSQ. In addition, one item evaluated self-rated health as a stress response, because it is reported to be a sensitive indicator of health status among community residents [16].

\section{Methods}

Study participants were employees of 50 small enterprises (2-49 employees) in X Prefecture, Japan. We asked a representative from each company to distribute self-administered questionnaires containing a Japanese version of the SOC scale [1], the BJSQ [10], the selfrated health item and socio-demographic items to their employees. A total of 1968 workers received the questionnaire. The purpose of the study was explained to the workers by their supervisors as being "to investigate the relationships between mental health status and job stress". They were instructed to anonymously complete the questionnaire and return it by postal mail. Of the 1968 workers invited to participate, 299 returned the questionnaire (15.2\%, 191 males and 108 females). They consisted of 186 office clerks, 38 sales representatives, 22 technical engineers, 16 service trade workers, eight information processing workers, eight technical experts, and 21 other workers of various types. The SOC scale [1] consisted of 13 items assessing comprehensibility, manageability and meaningfulness. Participants were asked to rate each item (1-7 points), and the points were summed into an SOC score. They were also asked to complete the BJSQ. Self-rated health was evaluated by asking participants to rate their own health status (1 "very healthy", 2 "rather healthy", 3 "not so healthy", 4 "unhealthy"); the rating was reversed for use in further analysis.

Associations between SOC and BJSQ scores, and selfrated health and socio-demographic variables were analyzed by U-tests, Chi-square tests and stepwise multiple regression using SPSS version 11.0 for Windows. In the multiple regression analysis, stress responses evaluated by the BJSQ and self-rated health scores were the dependent variables, and age, duration of work, managerial work (yes $=1$, no $=0)$, marriage ( married $=1$, not married $=0$ ), SOC scores, and job stressors assessed by the BJSQ were the independent variables. In the first models (model 1), all independent variables were entered into $(p \leq 0.05)$ or removed from $(p>0.05)$ the regression equations based on the significance level of the partial regression coefficient. In the second models (model 2), age, duration of work, managerial work, and marriage were entered into the equations as possible confounders, and then the stepwise method was used for the remaining variables.

Because gender differences have been found in the effects of SOC on health status $[7,17]$ and in the association between job stress and health behaviors [18], the analyses were performed separately for each gender.

The study design was reviewed and approved by the Research Ethics Committee of Mie University Graduate School of Medicine.

\section{Results}

The 299 participants had a mean age of 49.3 years $(\mathrm{SD}=$ 11.4). The mean SOC score was $58.8(\mathrm{SD}=14.0)$ with a Cronbach's alpha coefficient of 0.863 . Male participants were significantly older than female participants (mean age 50.7 versus 46.4 years, respectively, $p<0.05$ ). Males had significantly higher SOC scores $($ mean $=60.4, \mathrm{SD}=$ 13.7) than females (mean $=56.7, \mathrm{SD}=13.6, p<0.01$ ). There were no significant differences in BJSQ or selfrated health scores between the genders.

Participants were divided into two groups based on their SOC scores (above and below average, high and low SOC groups, respectively). Socio-demographic variables, BJSQ and self-rated health scores for each group are presented in Table 1. Participants in the high SOC group were older, more of them were married, and there were more managerial workers compared with the low SOC group. Job stressors (low support) and stress responses were lower in the high SOC group, while selfrated health scores were higher (indicating that participants in this group considered themselves healthier). 
Table 1 Differences in socio-demographic variables, selfrated health and BJSQ scores between SOC groups ${ }^{a}$

\begin{tabular}{|c|c|c|c|}
\hline & Higher SOC & Lower SOC & Differences $(p)^{\mathbf{b}}$ \\
\hline & \multicolumn{3}{|c|}{ Mean (standard deviation) } \\
\hline Age (years) & $52.2(11.1)$ & $45.6(10.5)$ & $<0.001$ \\
\hline \multicolumn{4}{|l|}{ BJSQ (scores) } \\
\hline \multicolumn{4}{|l|}{ Stressors } \\
\hline Job demand (quantity) ${ }^{c}$ & $6.8(2.4)$ & $6.3(2.3)$ & ns \\
\hline $\mathrm{Job}$ demand (quality) ${ }^{c}$ & $6.6(2.1)$ & $6.3(2.0)$ & ns \\
\hline Low job latitude & $5.3(1.5)$ & $6.5(1.8)$ & $<0.001$ \\
\hline Low support (supervisor) & $6.1(2.0)$ & $7.4(2.1)$ & $<0.001$ \\
\hline Low support (coworkers) & $6.5(1.9)$ & $7.4(2.1)$ & $<0.001$ \\
\hline
\end{tabular}

Low support (friends

and family)

\begin{tabular}{|c|c|c|c|}
\hline Physical job load ${ }^{c}$ & $3.2(0.9)$ & $3.2(0.8)$ & ns \\
\hline \multicolumn{4}{|l|}{ Stress responses } \\
\hline Tension & $5.5(2.0)$ & $7.6(2.6)$ & $<0.001$ \\
\hline Fatigue & $5.3(1.9)$ & $6.9(2.3)$ & $<0.001$ \\
\hline Anxiety & $5.4(1.8)$ & $6.7(2.0)$ & $<0.001$ \\
\hline Depression & $8.7(2.6)$ & $11.9(4.2)$ & $<0.001$ \\
\hline Subjective symptoms & $16.7(5.2)$ & 19.4(5.1) & $<0.001$ \\
\hline Vigor & $8.3(2.2)$ & $6.1(2.1)$ & $<0.001$ \\
\hline \multirow[t]{2}{*}{ Self-rated health(scores) } & $2.1(0.5)$ & $1.9(0.4)$ & $<0.01$ \\
\hline & Number (\%) & & \\
\hline Managerial workers & $119(62 \%)$ & $72(38 \%)$ & $<0.001$ \\
\hline Married & $139(55 \%)$ & $113(45 \%)$ & $<0.05$ \\
\hline
\end{tabular}

${ }^{a}$ SOC scores of 59 or above and 58 or less $(n=151$ and 146, respectively).

${ }^{b} \mathrm{U}$-test or chi-square test.

' Reversed item (the higher the score, the lower the demand or load).

Results of the multiple regression analyses are shown in Tables 2 and 3 for males, and Tables 4 and 5 for females. In models with and without controlling for socio-demographic variables, SOC was inversely associated with stress responses, i.e. tension, fatigue, anxiety, depression, and subjective symptoms, and was positively associated with vigor. Stress responses and self-rated health were adversely associated with job stressors such as job demand, low support and job aptitude in males. Similarly, SOC was inversely associated with tension, depression, and subjective symptoms, and was positively associated with vigor. Stress responses were adversely associated with job stressors such as job demand and low support in females. Marriage was inversely associated with depression in males, whereas it was positively associated with anxiety and depression in females. The correlation coefficients for the associations between SOC and the stress responses are presented in Table 6.

\section{Discussion}

Results of the multiple regression analysis

We found that among both male and female workers, stress responses such as tension, fatigue, depression, and
Table 2 Associations of stress responses and self-rated health with SOC and stressors in 190 male workers: model $1^{\text {a }}$

\begin{tabular}{|c|c|c|}
\hline $\begin{array}{l}\text { Dependent } \\
\text { variables }\end{array}$ & $\begin{array}{l}\text { Adjusted } \\
\mathrm{R}^{2}\end{array}$ & $\begin{array}{l}\text { Independent variables (partial } \\
\text { regression coefficient) }\end{array}$ \\
\hline \multirow[t]{2}{*}{ Tension } & $0.214^{* * *}$ & $\operatorname{SOC}\left(-0.408^{* * *}\right)$ \\
\hline & & Job demand (quantity) $\left(-0.193^{* *}\right)$ \\
\hline \multirow[t]{2}{*}{ Fatigue } & $0.306^{* *}$ & $\operatorname{SOC}\left(-0.390^{* * *}\right)$ \\
\hline & & Job demand (quantity) $\left(-0.357^{* * *}\right)$ \\
\hline \multirow[t]{3}{*}{ Anxiety } & $0.313^{* * *}$ & SOC $\left(-0.352^{* * *}\right)$ \\
\hline & & Job demand (quality) $\left(-0.349^{* * *}\right)$ \\
\hline & & Low support from supervisor $\left(0.187^{*}\right)$ \\
\hline \multirow[t]{4}{*}{ Depression } & $0.335^{* * *}$ & $\operatorname{SOC}\left(-0.411^{* * *}\right)$ \\
\hline & & $\underline{\text { Low support from supervisor }\left(0.197^{* *}\right)}$ \\
\hline & & Married $\left(-0.195^{* *}\right)$ \\
\hline & & Job demand (quantity) $\left(-0.158^{*}\right)$ \\
\hline $\begin{array}{l}\text { Subjective } \\
\text { symptoms }\end{array}$ & $0.092^{* * *}$ & $\operatorname{SOC}\left(-0.314^{* * *}\right)$ \\
\hline \multirow[t]{3}{*}{ Vigor } & $0.395^{* * *}$ & SOC $\left(0.275^{* *}\right)$ \\
\hline & & Low job aptitude $\left(-0.206^{* *}\right)$ \\
\hline & & Low support from supervisor $\left(-0.254^{* * *}\right)$ \\
\hline \multirow[t]{3}{*}{ Self-rated health } & $0.018^{*}$ & Physical job load $\left(-0.183^{* *}\right)$ \\
\hline & & Work duration $\left(0.182^{*}\right)$ \\
\hline & & Low support from colleagues $\left(-0.157^{*}\right)$ \\
\hline
\end{tabular}

a See Methods section for the stepwise multiple regression model procedure. ${ }^{b}$ Only those significantly associated with dependent variables are shown. ${ }^{*} p<0.05{ }^{* *} p<0.01{ }^{* * *} p<0.001$.

anxiety, as well as positive mood (vigor) were inversely associated with job stressors as measured by the BJSQ. SOC had the opposite association with stress responses, indicating that having a stronger SOC can reduce the adverse effects of job stress on psychological status among workers of both genders. Thus, not only psychiatric complaints as measured by the GHQ, but also job stress responses are affected by one's SOC.

Interestingly, marriage was positively associated with anxiety and depression in female workers, but inversely associated with depression in male workers. This is in contrast with a recent study conducted over 23 European countries on gender differences in depression, which demonstrated that a lower risk of depression was associated with marriage for both genders [19]. Marriagerelated psychological distress may be greater in Japanese women than men. It was reported that among infertile Japanese women, having a lack of husband support was associated with increased depression and anxiety [20].

According to a previous review, there is a strong association between SOC and mental health [21]. For example, because SOC is inversely associated with anxiety, hopelessness, depression, and perceived stressors, and positively associated with optimism, hardiness, self-esteem, self-efficacy, and social skills, it would appear that people with a stronger SOC tend to positively view their 
Table 3 Associations of stress responses and self-rated health with SOC and stressors in 190 male workers: model $2^{\mathrm{a}}$

\begin{tabular}{|c|c|c|}
\hline $\begin{array}{l}\text { Dependent } \\
\text { variables }\end{array}$ & $\begin{array}{l}\text { Adjusted } \\
\mathrm{R}^{2}\end{array}$ & $\begin{array}{l}\text { Independent variables (partial } \\
\text { regression coefficient) }\end{array}$ \\
\hline \multirow[t]{3}{*}{ Tension } & $0.231^{* * *}$ & Managerial work $\left(0.201^{*}\right)$ \\
\hline & & $\operatorname{SOC}\left(-0.415^{* * *}\right)$ \\
\hline & & Job demand (quantity) $\left(-0.162^{*}\right)$ \\
\hline \multirow[t]{3}{*}{ Fatigue } & $0.318^{* * *}$ & Age $\left(-0.185^{*}\right)$ \\
\hline & & $\operatorname{SOC}\left(-0.391^{* * *}\right)$ \\
\hline & & Job demand (quantity) $\left(-0.321^{* * *}\right)$ \\
\hline \multirow[t]{3}{*}{ Anxiety } & $0.300^{* * *}$ & $\operatorname{SOC}\left(-0.360^{* * *}\right)$ \\
\hline & & Job demand (quality) $\left(-0.332^{* * *}\right)$ \\
\hline & & Low support from supervisor $\left(0.180^{*}\right)$ \\
\hline \multirow[t]{4}{*}{ Depression } & $0.333^{* * *}$ & Married $\left(-0.212^{* *}\right)$ \\
\hline & & $\operatorname{SOC}\left(-0.428^{* * *}\right)$ \\
\hline & & Low support from supervisor $\left(0.188^{* *}\right)$ \\
\hline & & Job demand (quantity) $\left(-0.158^{*}\right)$ \\
\hline $\begin{array}{l}\text { Subjective } \\
\text { symptoms }\end{array}$ & $0.117^{* * *}$ & $\operatorname{SOC}\left(-0.381^{* * *}\right)$ \\
\hline \multirow[t]{4}{*}{ Vigor } & $0.395^{* * *}$ & Low support from supervisor $\left(-0.269^{* * *}\right)$ \\
\hline & & SOC $\left(0.254^{* *}\right)$ \\
\hline & & Physical job load $\left(-0.194^{* *}\right)$ \\
\hline & & Low job aptitude $\left(-0.195^{*}\right)$ \\
\hline
\end{tabular}

Self-rated health -

a See Methods section for the stepwise multiple regression model procedure.

${ }^{b}$ Only those significantly associated with dependent variables are shown.

${ }^{*} p<0.05{ }^{* *} p<0.01{ }^{* * *} p<0.001$.

health. The narrower SOC concepts, i.e. comprehensibility (how to understand reality) and manageability (ability to manage without great difficulty), may affect one's perception of stress. It is suggested that reducing negative job stress responses by supporting workers' self-perceptions as well as increasing their SOC and vigor can help them maintain a healthy life.

Eriksson et al. [22] demonstrated that SOC was significantly related to the self-rated health of 1013 Finland residents. We did not identify this association in our regression analyses, although the high SOC group had higher self-rated health scores than the low SOC group. This inconsistency between the studies may have resulted from differences in participant characteristics, and/or the smaller number of participants in our study. However, because self-rated health can predict one's ability to cope with stress to some extent, self-rated health is verified as a simple and effective indicator that can be used in health screening to predict changes in future health conditions [16].

\section{Characteristics of high SOC workers}

In our study, having a stronger SOC was associated with older age and job title (Table 1), although the groups
Table 4 Associations of stress responses and self-rated health with SOC and stressors in 101 female workers: model $1^{\text {a }}$

\begin{tabular}{|c|c|c|}
\hline $\begin{array}{l}\text { Dependent } \\
\text { variables }\end{array}$ & $\begin{array}{l}\text { Adjusted } \\
\mathrm{R}^{2}\end{array}$ & $\begin{array}{l}\text { Independent variables (partial } \\
\text { regression coefficient) }\end{array}$ \\
\hline \multirow[t]{2}{*}{ Tension } & $0.350^{* * *}$ & $\operatorname{SOC}\left(-0.490^{* * *}\right)$ \\
\hline & & Job demand (quantity) $\left(-0.321^{* *}\right)$ \\
\hline Fatigue & $0.228^{* * *}$ & Job demand (quantity) $\left(-0.488^{* * *}\right)$ \\
\hline \multirow[t]{4}{*}{ Anxiety } & $0.370^{* * *}$ & Job demand (quantity) $\left(-0.438^{* * *}\right)$ \\
\hline & & $\operatorname{Age}\left(0.321^{* * *}\right)$ \\
\hline & & $\operatorname{SOC}\left(-0.336^{* *}\right)$ \\
\hline & & Married $\left(0.192^{*}\right)$ \\
\hline \multirow[t]{5}{*}{ Depression } & $0.351^{* * *}$ & Low support from supervisor $\left(0.267^{*}\right)$ \\
\hline & & Job demand (quantity) $\left(-0.283^{* *}\right)$ \\
\hline & & $\operatorname{SOC}\left(-0.355^{* *}\right)$ \\
\hline & & Work duration $\left(0.260^{* *}\right)$ \\
\hline & & Married $\left(0.195^{*}\right)$ \\
\hline \multirow{2}{*}{$\begin{array}{l}\text { Subjective } \\
\text { symptoms }\end{array}$} & $0.123^{* *}$ & SOC $\left(-0.264^{*}\right)$ \\
\hline & & $\begin{array}{l}\text { Low support from friends and family } \\
\left(0.236^{*}\right)\end{array}$ \\
\hline \multirow[t]{2}{*}{ Vigor } & $0.259^{* * *}$ & SOC $\left(0.409^{* * *}\right)$ \\
\hline & & $\begin{array}{l}\text { Low support from friends and family } \\
\left(-0.268^{* * *}\right)\end{array}$ \\
\hline
\end{tabular}

Self-rated health -

${ }^{\text {a }}$ See Methods section for the stepwise multiple regression model procedure. ${ }^{b}$ Only those significantly associated with dependent variables are shown. ${ }^{*} p<0.05{ }^{* *} p<0.01{ }^{* * *} p<0.001$.

were based on the mean SOC score, rather than a validated cut-off point. This association may be attributable to a number of causes. First, older people are more likely to be appointed to managerial positions. Second, people who are promoted to management positions will develop stress tolerance with experience [23]. Third, people who have a consistently good mental health status and can manage stress tend to be selected for management positions [24]. The positive association of SOC with older age and job title seems reasonable if SOC is not an inborn or innate capacity but a learned sense that is acquired a posteriori through various life experiences and becomes deeply ingrained to shape personality [25].

The positive association between marriage and SOC identified in the present study may also be attributable to the age of married people. According to Eriksson and Lindström [26], SOC tends to increase with age through the whole life span. Whether the increases in individual SOC are an effect of natural selection of people (healthy people survive) or a question of people developing a strong SOC staying well is not clear. They suggest the second explanation. Males usually have a stronger SOC than females, although the differences are small [26]. This agrees with the observation of a stronger SOC in males than in females in the present study. 
Table 5 Associations of stress responses and self-rated health with SOC and stressors in 101 female workers: model $2^{\mathrm{a}}$

\begin{tabular}{|c|c|c|}
\hline $\begin{array}{l}\text { Dependent } \\
\text { variables }\end{array}$ & $\begin{array}{l}\text { Adjusted } \\
\mathrm{R}^{2}\end{array}$ & $\begin{array}{l}\text { Independent variables (partial } \\
\text { regression coefficient) }{ }^{b}\end{array}$ \\
\hline \multirow[t]{2}{*}{ Tension } & $0.345^{* * *}$ & $\mathrm{SOC}\left(-0.540^{* * *}\right)$ \\
\hline & & Job demand (quantity) $\left(-0.326^{* *}\right)$ \\
\hline Fatigue & $0.215^{* * *}$ & Job demand (quantity) $\left(-0.511^{* * *}\right)$ \\
\hline \multirow[t]{4}{*}{ Anxiety } & $0.370^{* * *}$ & Age $\left(0.338^{*}\right)$ \\
\hline & & Married $\left(0.206^{*}\right)$ \\
\hline & & Job demand (quantity) $\left(-0.435^{* * *}\right)$ \\
\hline & & $\operatorname{SOC}\left(-0.336^{* *}\right)$ \\
\hline \multirow[t]{3}{*}{ Depression } & $0.345^{* * *}$ & $\operatorname{SOC}\left(-0.370^{* *}\right)$ \\
\hline & & Job demand (quantity) $\left(-0.280^{* *}\right)$ \\
\hline & & Low support from supervisor $\left(0.270^{*}\right)$ \\
\hline $\begin{array}{l}\text { Subjective } \\
\text { symptoms }\end{array}$ & $0.113^{* *}$ & $\operatorname{SOC}\left(-0.353^{* *}\right)$ \\
\hline \multirow[t]{2}{*}{ Vigor } & $0.258^{* * *}$ & $\operatorname{SOC}\left(0.458^{* * *}\right)$ \\
\hline & & $\begin{array}{l}\text { Low support from friends and family } \\
\left(-0.257^{*}\right)\end{array}$ \\
\hline
\end{tabular}

\section{Self-rated health -}

a See Methods section for the stepwise multiple regression model procedure. ${ }^{b}$ Only those significantly associated with dependent variables are shown. ${ }^{*} p<0.05{ }^{* *} p<0.01{ }^{* * *} p<0.001$.

\section{Significance of SOC at workplace}

Horita [27] reported that SOC scores were significantly higher in healthy workers who had a high level of satisfaction with their work and life. According to a review of SOC and quality of life (QOL) [28], SOC seems to be a resource that directly enhances one's QOL, or enhances it via good health perceptions. A stronger SOC and increased job control resulted in better subjective feelings of well-being in a 1-year follow-up study of Japanese civil servants [29]. On the other hand, a weak SOC is assumed to have either a direct relationship with poor psychological well-being or an indirect relationship via the development of lifestyle problems such as a lack of exercise, obesity or smoking [30]. These findings, together with the "antagonistic" effects of having a weak SOC on responses to job stressors demonstrated in the present

Table 6 Correlation coefficients for SOC and stressors in 190 male and 101 female workers

\begin{tabular}{llc}
\hline & Males & Females \\
\hline Tension & $-0.425^{* * *}$ & $-0.525^{* * *}$ \\
\hline Fatigue & $-0.460^{* *}$ & $-0.236^{*}$ \\
\hline Anxiety & $-0.436^{* * *}$ & $-0.245^{*}$ \\
\hline Depression & $-0.504^{* *}$ & $-0.452^{* * *}$ \\
\hline Subjective symptoms & $-0.324^{* * *}$ & $-0.391^{* *}$ \\
\hline Vigor & $0.503^{* *}$ & $0.481^{* * *}$ \\
\hline Self-rated health & $0.243^{* *}$ & 0.081 \\
\hline${ }^{*} p<0.05^{* *} p<0.01{ }^{* * *} p<0.001$. & &
\end{tabular}

study, indicate that enhancing workers' SOC is essential for health at work and in daily life. Health education programs can improve workers' SOC [31], and therefore worksite intervention programs should be developed in further studies.

\section{Study limitations}

The present study was based on relatively small number of participants with a low response rate. This may have distorted the findings because the participants may have been more concerned about mental illness in relation to job stress than non-participants. Although it has been reported that the SOC and BJSQ scales have good reliability and/or validity $[13,14,26]$, it remains to be elucidated whether the different scales used in the present study really measured the same underlying psychological constructs. Our findings may have been dependent on the participants' general satisfaction or mood status, as the study was cross-sectional and used subjective-report variables. We only examined stress-related outcomes. In future studies, the prevalence/ incidence of somatic or psychological disorders should be used as outcomes in relation to SOC and the stressors measured by the BJSQ; because, for example, coronary heart disease risk is significantly related to job stress [11,12]. A well-designed longitudinal study following a larger number of participants is necessary to further confirm that SOC reduces the adverse health effects of job stress.

\section{Conclusion}

It is suggested that increasing one's SOC may reduce their negative job stress responses and subjective symptoms, and enhance their vigor. The positive association of SOC with older age and job title indicates that SOC is not an inborn or innate capacity but a learned sense. Interventions for increasing workers' SOC should be developed.

\section{Competing interests}

The authors declare that they have no competing interests.

\section{Acknowledgments}

The authors thank Dr. Yoshihiko Yamazaki, Graduate School of Medicine, The University of Tokyo, for his valuable suggestions. The present study was supported by Grants-in-Aid from the Ministry of Health, Labour and Welfare of Japan.

\section{Authors' contributions}

$\mathrm{KU}$ and $\mathrm{KY}$ equally contributed to the study design, data collection, analysis, interpretation, and manuscript preparation. HI helped with manuscript preparation as well as data analysis and interpretation. All authors read and approved the final manuscript.

Received: 15 October 2011 Accepted: 20 May 2012

Published: 20 May 2012

\section{References}

1. Yamazaki Y: SOC, a theory on salutogenesis and health promoting ability from newly developed view points for health. Quality Nursing 1999, 5:824-832 (in Japanese). 
2. Antonovsky A: Health, stress, and coping: New perspective on mental and physical well-being. Jossey-Bass Publishers: San Francisco, CA; 1979.

3. Antonovsky A: Unraveling the mystery of health, How people manage stress and stay well. San Francisco, CA: Jossey-Bass Publishers; 1987 [Translated in to Japanese by Yamazaki Y and Yoshii K: Tokyo, Yushindo 2001].

4. Feldt T, Lintula H, Suominen S, Koskenvuo M: Structural validity and temporal stability of the 13-item sense of coherence scale: Prospective evidence from the population-based HeSSup study. Quality of Life Research 2006, 16:483-493.

5. Feldt $\mathrm{T}$ : The role of sense of coherence in well-being at work: analysis of main and moderator effects. Work Stress 1997, 11:134-147.

6. Gilbar O: Relationship between burnout and sense of coherence in health social workers. Soc Work Health Care 1998, 26:39-49.

7. Takayama T, Asano Y, Yamazaki Y, Yoshii K, Nagasaka Y, Fukada J, Furusawa Y, Takahashi S, Seki Y: Sense of coherence, stressful life events and psychological health. Jpn J Public Health 1999, 11:965-975 (in Japanese).

8. Nasermoaddeli A, Sekine M, Hamanishi S, Kagaminori S: Associations of sense of coherence with sickness absence and reported symptoms of illness in Japanese civil servants. Industrial Health 2003, 45:231-233.

9. Haoka T, Sasahara S, Tomotsume Y, Yoshino S, Maeno T, Matsuzaki I: The effect of stress-related factors on mental health status among resident doctors in Japan. Medical Education 2010, 44:826-834.

10. Japan Industrial Safety and Health Association (Website): Stress Check http://www.jisha.or.jp/mental_health/stress_check.html (access on August 15, 2011).

11. Johnson JV, Hall EM: Job strain, workplace social support, and cardiovascular disease: a cross-sectional study of a random sample of the Swedish working population. American J Public Health 1988, 78:1336-1342

12. Johnson JV, Hall EM, Theorell T: Combined effects of job strain and social isolation on cardiovascular disease morbidity and mortality in a random sample of the Swedish male working population. Scand J Work Environ Health 1989, 15:271-279.

13. Shimomitsu T, Haratani T, Ohno Y, et al: In The Ministry of Labour sponsored grant for the prevention of work-related illness, The 1999 Report. Edited by Kato M. Tokyo: Tokyo Medical College; 2000:126-164 (in Japanese).

14. Kawada T, Otsuka T: Relationships between job stress, occupational position and job satisfaction using a brief job stress questionnaire. Work 2011, 40:393-399.

15. Urakawa K, Yokoyama K: Sense of Coherence (SOC) may reduce the effects of occupational stress on mental health status among Japanese factory workers. Industrial Health 2009, 47:503-508.

16. Idler EL, Benyamini Y: Self-rated health and mortality: a review of twentyseven community studies. J Health Soc Behavior 1997, 38:21-37.

17. Ogawa $Y$, Nakamura $H$, Nagase $H$, Ogino $K$, Ooshita $Y$, Tsukahara S: Structural analysis for psychosocial factors including health locus of control (HLC) and sense of coherence (SOC) associated with lifestylerelated diseases. Jpn J Hyg 2001, 55:597-606 (in Japanese).

18. Hellerstedt W, Jeffery RW: The association of job strain and health behaviours in men and women. International Journal of Epidemiology 1997, 26:575-583.

19. deVelde SV, Bracke P, Levecque P: Gender differences in depression in 23 European countries. Cross-national variation in the gender gap in depression. Social Science and Medicine 2010, 71:305-313.

20. Matsubayashi H, Hosaka T, Izumi S, Suzuki T, Kondo A, Makino T: Increased depression and anxiety in infertile Japanese women resulting from lack of husband's support and feeling of stress. General Hospital Psychiatry 2004, 26:398-404.

21. Eriksson M, Lindström B: Antonovsky's sense of coherence scale and the relation with health; a systematic review. J Epidemiol Community Health 2006, 60:376-381.

22. Eriksson M, Lindström B, Lilja J: A sense of coherence and health. Salutogenesis in a societal context: Ålanad, a special case? J Epidemiol Community Health 2007, 61:684-688.

23. Haratani T: Factors affecting mental health status of KANRISHOKU. Digest of Science of Laboure 1993, 48:336-339 (in Japanese).

24. Poppius E, Tenkanen L, Kalimo R, Heinsalmi P: The sense of coherence, occupation and the risk of coronary heart disease in the Helsinki Heart Study. SocSci Med 1991, 49:109-120.

25. Stephens T, Culberg C, Joubert N: Mental health of the Canadian population: a comprehensive analysis. Chronic Dis 1999, 20:118-126.
26. Eriksson M, Lindström B: Validity of Antonovsky's sense of coherence scale: a systematic review. J Epidemiol Community Health 2005, 59:460-466.

27. Horita M, Koshida E, Hirao Y, Matsuo Y, et al: Relationships of Sense of Coherence (SOC) scale (short-form) to stress response and consultation with physicians. The Teishinigaku 2007, 59:246-249 (in Japanese).

28. Eriksson M, Lindström B: Antonovsky's sense of coherence scale and its relation with quality of life; a systematic review. J Epidemiol Community Health 2007, 61:938-944.

29. Nasermoaddeli A, Sekine M, Hamanishi S, Kagamimori S: Associations between Sense of Coherence and psychological work characteristics with changes in Quality of Life in Japanese civil servants; A 1-year follow-up study. Industrial Health 2003, 41:236-241.

30. Matsuzaki I, Sagara T, Ohshita Y, Nagase H, Ogino K, Eboshida A, Sasahara S, Nakamura H: Psychological factors including sense of coherence and some lifestyles are related to general health questionnaire-12 (GHQ-12) in elderly workers in Japan. Environmental Health and Preventive Medicine 2007, 12:71-77.

31. Nakamura H, Matsuzaki I, Sasahara S, Hatta K, Nagase H, Oshita Y, Ogawa Y, Nobukini $Y$, Kambayashi $Y$, Ogino K: Enhancement of a sense of coherence and natural killer cell activity occurred in subjects who improved their exercise habits through health education in the workplace. Journal of Occupational Health 2003, 45:278-285.

doi:10.1186/1756-0500-5-247

Cite this article as: Urakawa et al:: Sense of coherence is associated with reduced psychological responses to job stressors among Japanese factory workers. BMC Research Notes 2012 5:247.

\section{Submit your next manuscript to BioMed Central and take full advantage of:}

- Convenient online submission

- Thorough peer review

- No space constraints or color figure charges

- Immediate publication on acceptance

- Inclusion in PubMed, CAS, Scopus and Google Scholar

- Research which is freely available for redistribution 